\title{
10 Drying Process
}

The addition of water is required to hydrate the paste and make it workable in order to shape a ceramic. The amount of water that clays can absorb is usually between 15 and $50 \%$ of their weight. As already explained, the water used for modelling pottery provides the paste with certain elements in very small proportions, thus altering its chemical composition. An example is the use of sea water, since this kind of water has a high chlorides content that remains in the paste after the water is evaporated (Echallier, 1984; Morales, 2005; Potter et al., 2005).

Once the paste has been hydrated and the vessel shaped, the evaporation of the water absorbed must be slow, gradual and uniform with the aim to minimize differential stress in the diverse parts that form the pottery. Ceramic does not dry as fast in its thicker parts as it does in the thinner walls, which dry more quickly and easily. The drying time required for a ceramic can vary between several days or even weeks depending on the properties of the clay, the wall thickness and the way the paste is prepared. The most important variables involved in the dehydration process are the area of the vessel exposed to the weather as well as the temperature, humidity and location in which the drying process takes place, which may be in the open air or not. However, the factor that mostly affects the behaviour of the paste during dehydration is the type and amount of clay minerals which are present in the raw material and, to a lesser extent, the arrangement of the pores in the matrix (Banning, 2005; Cuomo Di Caprio, 1985; Djordjevic, 2003; Gibson and Woods, 1990; Morales, 2005; Van der Leeuw, 1984).

This phase of the chaîne opératoire will be succinctly explained, since P. Rice (1987) has already developed a detailed description of the behaviour of ceramics during the drying and the different stages that this process involves. During the drying process, the ceramic object experiences a significant decrease in volume and weight that is particularly noticeable in the constant-rate period of drying, when more than $3 / 5$ of the water is removed from the pottery. During the constant-rate period the loss of capillary water that evaporates from the clay due to air temperature takes place causing a gradual shrinkage of the walls and the subsequent contact between the clay particles. As the water evaporates it also leaves a porous microstructure in the matrix. The drying rate is then determined by several factors such as temperature, humidity, water content, pore size, etc. The end of this drying process is known as the "critical point", when the weight of the pottery is stabilized and the paste is already rigid and in a leather-hard stage. However, after this process not all the water absorbed by the clay minerals is removed: critical moisture content also known as "pore water" still remains in the pottery. The amount of pore water occurring in the paste depends on the moisture present in the atmosphere (Carter, 2002; Khalfi and Blanchart, 1999; Morales, 2005; Rice, 1987). 
Thus, the next kind of water that evaporates from the ceramic is the pore water that remains isolated in the micro-pores formed between the clay particles due to the shrinkage that took place during the constant-rate period of drying. In this second phase of drying, known as the falling-rate period, the drying rate is determined by the water's ability to migrate through the pores from the core of the wall to the surfaces of the vessel. Therefore, the dehydration of the pottery is slower than in the previous drying stage (Gibson and Woods, 1990; Morales, 2005; Rice, 1987). At the end of the drying process and before firing, the paste has both a macro-porous and microporous structure due to the evaporation of water from the lamellar structure of the clay minerals. In the end, not all the water absorbed is completely removed and some remains in the core of the wall. The total evaporation of the pore water occurs during the firing process, thus giving place to the formation of more micro-pores in the fabric (Echallier, 1984; Worrall, 1975). 